\title{
Linguistic Validation of the Phenylketonuria - Quality of Life (PKU- QOL) Questionnaire Into Brazilian Portuguese
}

Journal of Inborn Errors of Metabolism \& Screening 2019, Volume 7: e20180001 DOI: 10.1590/2326-4594-JIEMS-2018-0001

\author{
Fabíola Vicente'; Elaina Jurecki²; Daniela Giovannetti'; \\ Ana Rita Ferreira ${ }^{3}$; Efigênia Leite ${ }^{4}$; Luciana Giugliani ${ }^{5}$ \\ and Catherine Acquadro 6
}

\begin{abstract}
The phenylketonuria - quality of life (PKU-QOL) questionnaire was developed to assess the impact of phenylketonuria (PKU) and its treatment on the health-related quality of life (HRQL) of patients and their caregivers. Available in four versions (child, adolescent, adult and parent), it was developed and validated in eight countries. The objective of this study was to linguistically validate the PKU-QOL questionnaire in Brazilian Portuguese for use in Brazil by clinicians who take care of PKU patients. The translation method used a standard linguistic validation process. The British English version served as a basis for translation. No major cultural or semantic issues were found during the process. The main difficulty was the use of the acronym "PKU" in the first translations. During the cognitive interviews, respondents made the confusion between the disease itself and the food supplement since it is written "PKU" or "COMIDA-PKU" on the packaging of the product. To overcome this issue, it was decided to use fenilcetonúria (fenil) or fenil alone throughout all versions. The PKU-QOL will be valuable for Brazilian healthcare providers in individualizing treatment and managing patients with PKU.
\end{abstract}

\section{Keywords}

phenylketonuria, PKU-QOL questionnaire, health-related quality of life, translation, linguistic validation, cross-cultural.

\section{Introduction}

Phenylketonuria (PKU), or phenylalanine hydroxylase deficiency, is a rare autosomal recessive disease, triggered by the deficiency of the hepatic enzyme, phenylalanine hydroxylase (PAH) that oxidizes the essential amino acid phenylalanine (PHE) in tyrosine (TYR) [1]. This error causes increased PHE blood concentrations and leads to a toxic accumulation in the brain, resulting in cognitive deficiencies, emotional disturbance and psychosocial disabilities $[1,2]$.

Current treatment for PKU involves life-long dietary restrictions in PHE excluding most protein-containing foods. Medical foods are an essential component of this diet [3] with the goal of maintaining blood PHE in the range of 120-360 $\mu \mathrm{mol} / 1$ [3]. Medical foods for PKU include essential TYR and varying quantities of carbohydrate, fat, vitamins, and minerals, and provide the amino acids needed for normal growth and development $[4,5]$. The only approved medicinal product for PKU, in Canada, Brazil, Japan, the European Union, and the USA, is sapropterin dihydrochloride.

\author{
${ }^{1}$ BioMarin Brasil Farmacêutica Ltda., São Paulo, SP, Brazil \\ 2BioMarin Pharmaceutical Inc., Novato, CA, USA \\ ${ }^{3}$ APAE São Paulo, São Paulo, SP, Brazil \\ ${ }^{4}$ APAE Salvador, Salvador, BA, Brazil \\ ${ }^{5}$ Hospital de Clínicas de Porto Alegre, Porto Alegre, RS, Brazil \\ ${ }^{6} \mathrm{Mapi}$, an ICON plc Company, Patient-Centered Sciences, Lyon, France
}

Received October 2, 2018. Accepted for publication November 14, 2018.

\section{Corresponding Author:}

Catherine Acquadro, MD, Mapi, an ICON plc Company, Patient-Centered Sciences, 27 rue de la Villette, 69003 Lyon, France

Email: Catherine.Acquadro@iconplc.com 
Journal of Inborn Errors of Metabolism \& Screening

Even treated, PKU patients may experience psychological and neurocognitive problems [6]. In a systematic literature review, Enns et al. [7] reported that overall intellectual functioning and specific neuropsychological abilities may be suboptimal in patients having either high or fluctuating blood PHE concentrations and treated with diet only. Executive dysfunction in working memory, mental flexibility, organizational strategy and conceptual reasoning were accounted. They also described attentional problems leading to negative impacts on academic progress, as well as on self-esteem and emotional development. Regarding the assessment of health-related quality of life (HRQL) outcomes, the same authors [7] reported contrasting results. Six studies were reviewed: two of them described optimal outcomes, i.e., HRQL comparable to normal controls [8, 9], and four presented suboptimal results [10-13]. However, more recent studies suggest that the HRQL of patients with PKU is often comparable to that of the general population [14-18]. Most of these studies use generic instruments to evaluate HRQL, i.e., questionnaires intended for use irrespective of the underlying disease. The lack of specificity of these generic questionnaires, not specifically designed to address the impact of PKU and its treatment on patients' lives, might be the reason for observing normal HRQL outcomes. Those generic questionnaires fail to assess more subtle problems that may be experienced by individuals with PKU. For instance, Ziesch et al. [14] used the KINDL (Kinder Lebensqualität), a generic measure of HRQL for children (originally developed in German), to assess the impact of $\mathrm{BH}_{4}$ on quality of life. They noticed that HRQL results conflicted with personal reports from children and parents, and suggested that these outcomes could be related to the use of the KINDL which did not capture aspects that mattered to the patients. They concluded that the development of a specific disease-related PKU instrument to assess HRQL could be a useful addition to the field. As such, a HRQL PKU-specific instrument should be able to detect decrease in specific domains important to the life of patients with PKU as well as potential improvements in these domains due to therapeutic interventions.

The phenylketonuria - quality of life (PKU-QOL) questionnaire was developed to address these issues [19]. The PKU-QOL is the first self-administered instrument developed for patients with PKU and their caregivers which assesses three domains important to the patients: PKU symptoms, PKU in general (i.e., physical, emotional, social and overall impacts of $\mathrm{PKU}$ ), and the impact of treatment. There are four versions of the PKU-QOL: three are age-specific [Child (9-11 years old) PKU-QOL (40 items), Adolescent (12-17 years old) PKU-QOL (58 items), Adult PKU-QOL (65 items)], and one version, Parent PKU-QOL (54 items), enables the evaluation of the HRQL of children by their caregivers as well as an assessment of the parents' HRQL. The four versions share a similar structure, but reflect the specific realities of each population. The PKUQOL was developed and validated in eight countries (France, Germany, Italy, The Netherlands, Spain, Turkey, the United Kingdom (UK) and the United States of America (USA) [19, 20]).
The aim of this study was to adapt and linguistically validate the PKU-QOL in Brazilian Portuguese for use in Brazil by healthcare providers to evaluate the HRQL of patients with PKU.

\section{Methods}

\section{Linguistic Validation Process}

The linguistic validation process [21] used to develop the Brazilian Portuguese version of the PKU-QOL was in compliance with the recommendations of the International Society for Pharmacoeconomics and Outcomes Research [22, 23]. The British English questionnaire served as a basis for the validation process of the Brazilian Portuguese PKU-QOL questionnaire. The process, conducted by a coordinating center (Mapi Language Services), consisted of five steps (Figure 1).

The first step involved the conceptual analysis of the original British English PKU-QOL questionnaire, in collaboration with the sponsor of the project, in order to provide the translation team with a document explaining the meaning of each instruction, item and response options and suggesting terms to denote each concept. This was the basis for ensuring that the Brazilian Portuguese version of the PKU-QOL was faithful to the meaning of the original.

Secondly, the original British English PKU-QOL was translated through a dual process of forward-backward translation and reviews by a local team leader and the project manager of the coordinating center who supervised the whole process. Two different Brazilian Portuguese versions were developed independently by two native Brazilian translators living in Brazil; these two versions were used to create one single translation called the reconciled version (i.e., Step 2, forward translation step). The reconciliation process was performed during a meeting involving the two forward translators and the local team leader of the project in Brazil. This reconciled version was back-translated into English (Step 3) and compared to the original British PKU-QOL to check for discrepancies and control the quality of the Brazilian Portuguese reconciled version. The backward translation was performed by a translator blinded to the original US version, who was a native English speaker, fluent in Brazilian Portuguese, and living in Brazil. This document was reviewed by the developer of the original US questionnaire, the local team leader and the project manager of the coordinating center. The objective was to check for discrepancies with the original version due to inaccurate wording in the Brazilian Portuguese reconciled version.

In Step 4 (i.e., testing), the resulting Brazilian Portuguese version (following forward and backward translation steps) was reviewed by three dieticians who provide care to PKU patients, living in different areas of Brazil, to check for the accuracy of the wording and agree on wording that would take into consideration the differences of language between regions. Then, the dieticians-revised version was used for in-depth cognitive 


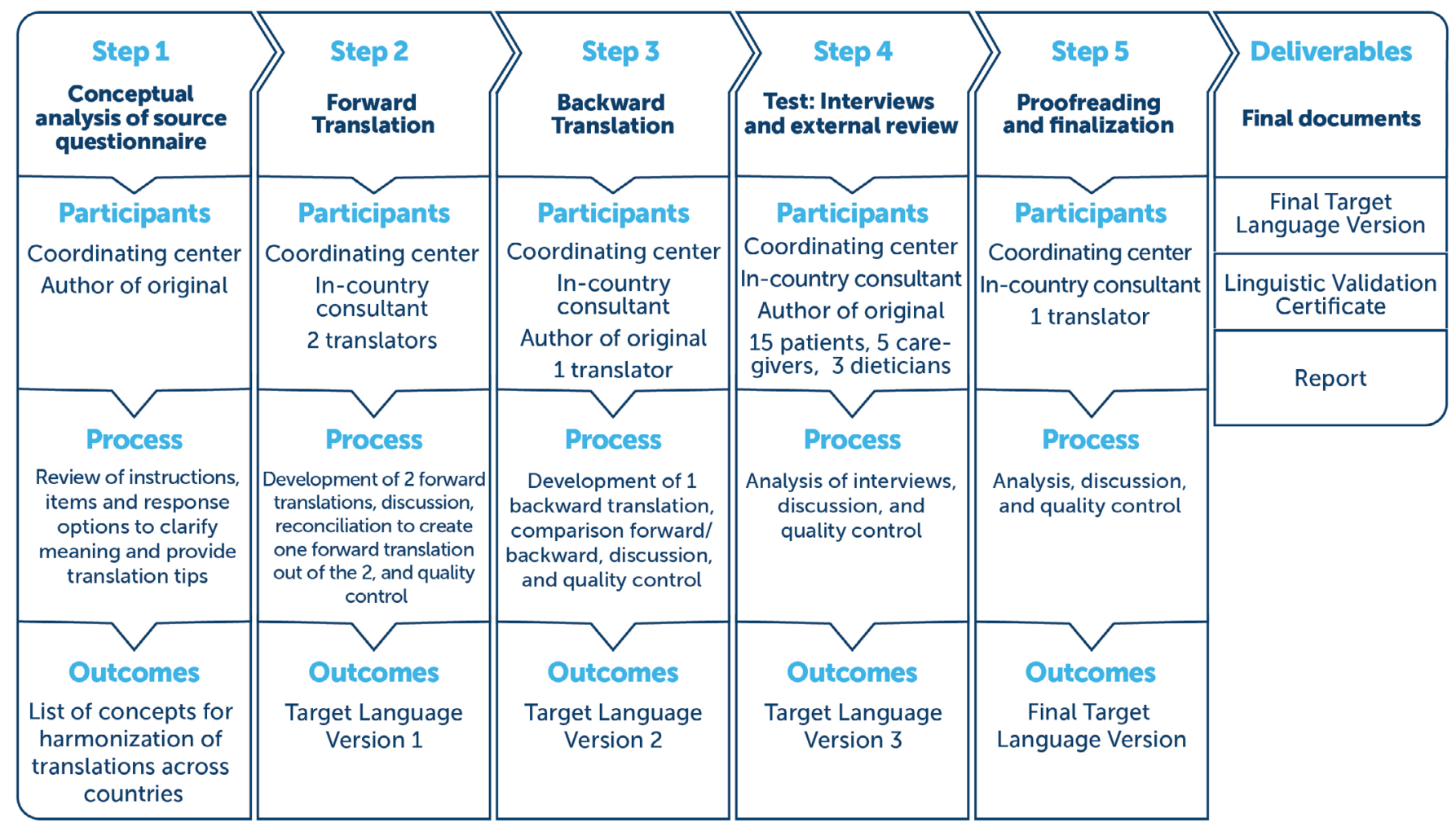

Figure 1. Linguistic Validation Process

individual interviews with patients and caregivers. The objective was to investigate the appropriateness, understandability and clarity of the Brazilian Portuguese PKU-QOL questionnaire. Participants were asked to comment on their understanding of each part of the questionnaire (i.e., instructions, questions and response categories) and suggest alternative formulations where wording was thought to be problematic. The interviewer carefully explored if the patients and their caregivers had a clear understanding of the concept behind each item (Were the participants able to provide the meaning of each item?), and if not why (i.e., inaccurate translation or concept not culturally relevant?). In case of any difficulties, the interviewer also asked for alternative wording. For each instruction, item and response options, all problems identified and suggestions for changes were gathered in a summary grid and analyzed to produce the final version.

Finally, two proof-readings were conducted by two translators working independently [i.e., the in-country consultant and one translator new to the study (step 5)].

\section{Participants}

Patients with a diagnosis of PKU were recruited through the Associação de Pais e Amigos dos Excepcionais (APAE) in São Paulo, Brazil who agreed to participate in this study. The APAE was asked to recruit patients of specified ages according to the questionnaire being evaluated. Patients and their caregivers were included if they agreed to participate in the interviews, provided informed content, and were native Brazilian Portuguese speakers residing in Brazil. Patients were not recruited based on their phenotype.

\section{Analysis}

The linguistic validation report was reviewed to identify difficulties and problematic issues, as well as the solutions proposed to overcome them. The types of difficulties were categorized as Cultural (C), Idiomatic (I), Semantic/conceptual (S) or Syntactic (Sy) (Table 1).

\section{Results}

\section{Participants}

Interviews were conducted with 15 patients and 5 caregivers of patients with PKU (Table 2). The Brazilian Portuguese versions of the PKU-QOL were administered as follows: Child PKU-QOL to five children; Adolescent PKU-QOL to five adolescents; Adult PKU-QOL to five adults; and Parent PKU-QOL to five parents of the children/adolescents already recruited to test the children and adolescent versions.

The questionnaire on the whole was reported to be clearly worded and easy to understand. The instructions, as well as the response choices, were found to be straightforward and free from ambiguity. For each item, respondents had no difficulty in choosing their answer. 
Table 1. Categorization of translation difficulties

\begin{tabular}{ll}
\hline Category & Definition \\
\hline Cultural (C) & A word or formulation in the original is culturally loaded in the target context due to societal or religious customs (e.g., \\
eating habits in Asian countries). The usage of certain words or phrases based on the culture of a given society may be & improper in the target language. \\
& For instance, starchy foods (e.g., potato, bread, etc.), starchy foods (e.g., rice, pasta, chapatti, etc.). \\
& Semantics concerns meanings, which are both denotative, i.e., the literal word (lexis), and connotative, namely the set of \\
& cultural and/or subjective associations implied by a word in addition to its literal explicit meaning. This category includes \\
lexical differences. & For instance, meet your responsibilities, meet your duties, or meet your obligations. \\
& The practicalities of how a language is used in its everyday context are different between the source and target language. \\
& For example, one language may have more social registers than another (there are a number of different forms of addressing \\
a person in Japanese, whereas English may only have one) and the idiosyncrasies of one language (repetitions, focus on & particular words, use of idiomatic expressions, etc.) may not be found in another. \\
Idiomatic/Pragmatics (I) & For instance, I feel downhearted and blue, I feel down and sad. \\
& Syntactic difficulties correspond to specific aspects related to sentence structure, grammar, punctuation. The structure \\
and grammar of the source and target language may diverge. For example, there is no grammatical form for the past \\
tense in Tagalog. \\
For instance, How flexible have you been finding...? How flexible have you found...?
\end{tabular}

Table 2. Demographic characteristics of the cognitive interview participants

\begin{tabular}{|c|c|c|c|c|}
\hline \multirow[b]{2}{*}{ Characteristics } & \multicolumn{4}{|c|}{ Participants } \\
\hline & $\begin{array}{l}\text { Child } \\
(n=5)\end{array}$ & $\begin{array}{l}\text { Adolescent } \\
\qquad(n=5)\end{array}$ & $\begin{array}{l}\text { Adult } \\
(n=5)\end{array}$ & $\begin{array}{c}\text { Parent } \\
(n=5)\end{array}$ \\
\hline Gender: Males/Females & $4 / 1$ & $4 / 1$ & $0 / 5$ & $3 / 2$ \\
\hline
\end{tabular}

The comprehension rates for each category of respondents were the following: children $=90 \%$; adolescents $=91 \%$; adults $=88 \%$; parents $=98 \%$. Those rates correspond to the ratio between the number of respondents who had no difficulties in understanding divided by the total number of respondents. Understanding of the title of each domain, each instruction sentence, all items and their corresponding response category was taken into consideration for the rate calculation.

\section{Translation Issues}

All issues are presented in detail in Table 3.

The main difficulty with all four versions was the use of the acronym "PKU" in the first forward translations. In the original UK, "PKU" refers to the disease, i.e., phenylketonuria. However, during the cognitive interviews, respondents made the confusion between the disease itself and the food supplement since it is written "PKU" or "COMIDA-PKU" on the packaging of the product. Most of the respondents understood PKU as the supplement and not the disease, even though explained in the instructions. Patients know the disease as "fenilcetonúria" or "fenil", but never as "PKU." Therefore, it was very confusing to keep "PKU" (referring to the disease), "PKU food," and "PKU diet" as stated in the original UK version.

Several possibilities were suggested:

1. To keep the acronym PKU when referring to the disease but adding an extra explanation in the instructions, such as:

- "On this questionnaire when you read PKU, it means we are asking about fenilcetonúria also called fenil."

- "When you read Formula Metabolica, it means we are asking about the product/powder prescribed by the dietician."

- "When you read PKU diet it means we are asking about the special diet you have to follow."

2. Another option was training every participant before starting the study, explaining what each term referred to. 
3. The third option was not to use the acronym PKU and use fenilcetonúria (fenil) throughout all versions.

Option 3 was chosen following the advice of the dieticians, and discussions with the sponsor. However, to avoid the repetition of the two words throughout the questionnaire and redundancy, it was decided to replace PKU by: a) fenilcetonúria (fenil), in the title of each version, in the name of the concerned domains (i.e., Diet and Supplement, Daily life, and Feelings in general), and in the instructions, and b) fenil, in the items (i.e., statements and questions of the PKUQOL).

Table 3. Most problematic PKU-QOL translation issues classified by version (Children, Adolescents, Adults and Parents) and by type of difficulty (Diff.) - Cultural (C), Idiomatic (I), Semantic (S) and Syntactic (Sy)

\begin{tabular}{|c|c|c|c|c|c|c|}
\hline Title/Instructions/Items/ & & & ${ }^{\S}$ Ste & & & \\
\hline $\begin{array}{l}\text { Response Categories } \\
\text { Original UK version }\end{array}$ & Diff.* & F/B* & $\mathbf{C l} *$ & $\mathbf{R} *$ & Description & Solutions \\
\hline
\end{tabular}

Common to PKU-QOL all four versions (Children, Adolescents, Adults and Parents)

Or PKU-QOL three versions: either Adolescents, Adults and Parents or Children, Adolescents, Adults

Respondents were confused during the interviews by the use of PKU in the Brazilian version,

Use of "PKU" in title, instructions, name of domain, and items S as for them PKU refers to the name of the supplement, i.e., PKU COMIDA, and not to the disease, i.e., phenylketonuria.
The solution was found by the dieticians and the sponsor who suggested replacing PKU by: fenilcetonúria (fenil), in the title of each version, in the name of the concerned (i.e., Diet and Supplement, Daily life, and Feelings in general), and in the instructions, and fenil, in the items.

Main Instructions

Children: By supplement or amino acid mixture, we mean the medicine powder or drink that you have to take every day.

Adolescents: By supplement or amino acid mixture, we mean the product or liquid prescribed by your doctor.

Adults: By supplement or amino acid C/S/Sy mixture, we mean the product or liquid (for example milk, powder) prescribed by your doctor.

Parents: By supplement or amino acid mixture, we mean the product or liquid (for example milk, powder) prescribed to your child by their doctor.
In Brazil the supplement is not a drink or liquid, but a powder. In addition, the dieticians suggested using the common name used in Brazil for supplement or amino acid mixture.

The syntax of the literal translation was an issue for the children, adolescents and adults respondents.

For instance, two children had difficulties with the use of "by" and "nos referimos" for "we mean", which were too sophisticated for their age.
The word "bebida" or "liquido" was deleted from the initial translation. The literal translation of "supplement or amino acid mixture" was replaced by the correct medical term, i.e., "fórmula metabólica" (BT**: metabolic formula). The sentence was simplified by using "Fórmula metabólica" as the subject and by deleting any reference to "by" and "we mean." For instance, for the children version: Fórmula metabólica é o pó que você tem que tomar todos os dias (BT**: Metabolic formula is the powder you have to take every day).
This sentence was not problematic. However, the dieticians insisted on adding a clarification about the necessity to give only one answer for each question.

\footnotetext{
"You can only mark " $X$ " per question" (Você só pode assinalar um "X" por pergunta) was added in all versions.
} 
Table 3. Cont.

\begin{tabular}{lllllll}
\hline Title/Instructions/Items/ & & \multicolumn{2}{c}{ LV Step } & & Description \\
$\begin{array}{l}\text { Response Categories } \\
\text { Original UK version }\end{array}$ & Diff.* & F/B* & Cl* & $\mathbf{R}^{*}$ & & Solutions \\
\hline Instructions for Domains & & & & & \\
\hline
\end{tabular}

\begin{tabular}{|c|c|c|c|c|c|}
\hline $\begin{array}{l}\text { For each sentence, please tick the } \\
\text { box that best applied to you. } \\
\text { (used in Adolescent, Adult and Parent } \\
\text { versions) }\end{array}$ & $\mathrm{S}$ & $\checkmark$ & $\checkmark$ & $\begin{array}{l}\text { Translators and dieticians argued } \\
\text { about the translation of "box." } \\
\text { At first, it was translated by } \\
\text { the diminutive "quadradinho" } \\
\text { which was judged too childish } \\
\text { by the dieticians who proposed } \\
\text { "alternativa." This option was not } \\
\text { accepted and it was decided to } \\
\text { use "quadrado." }\end{array}$ & $\begin{array}{l}\text { "Tick the box" was translated by "marque } \\
\text { o quadrado" (BT**: mark the box). This } \\
\text { was applied for repeated instructions using } \\
\text { the "tick the box" terms throughout the } \\
\text { questionnaire. }\end{array}$ \\
\hline
\end{tabular}

Two children respondents had difficulties in understanding "mais

Children - Item 10. In the past 7 days, I needed longer to think about things than my friends at school Adolescents, Adults - Item 6a. In the past 7 days, I needed longer to think about things (for example, schoolwork) than friends my age Parent - Item 6a. In the past 7 days, my child needed longer to think about things than other children their age

Domain "YOUR PKU DIET AND SUPPLEMENTS" tempo" (longer).

Two children and two adolescent respondents had difficulties in understanding the literal translation of "think about things",

i.e., "pensar sobre coisas."

Same issue with two adult respondents who either thought it was too vague, or too strange. Another respondent suggested using "racionar" (to reason), which was found more acceptable by all respondents of this group.
Translators decided to replace "pensar sobre coisas" which was found too vague by "racionar (to reason), following the suggestion of the adult respondents. The Parent version was harmonized accordingly. low protein food

(used in several items in all versions)

estimate protein (exchanges)

(used in Adolescent, Adult and Parent

versions)
"Low protein food" was an issue. Dieticians indicated that "low protein" (baixa proteina) is commonly named "baixo teor de fenil." The problem was that this solution would have led to using "fenil" with 2 different meanings (i.e., PKU and protein).

For the sake of accuracy, the initial translation of protein (proteína) was challenged by the dieticians.
Translators chose to use a periphrasis, i.e., "food with low level of protein for phenylketonuria" (comida de baixo teor de proteína para fenil).

"Proteina" was replaced by "fenilalanina" (BT**: phenylalanine). 
Table 3. Cont.

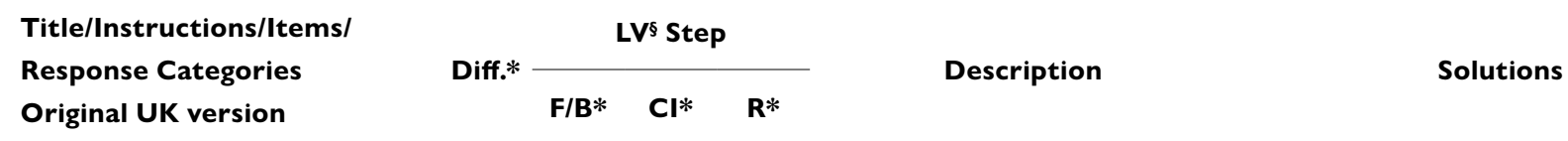

Domain "YOUR DAILY LIFE WITH PKU”

\section{Instruction}

Children - Following are some things that some children may experience when living with PKU.

Adolescents, Adults - Following are some things that people may experience when living with PKU. Parents - Following are some things that parents of children with PKU may experience when living with PKU.
During the interviews, two children had difficulties with the translation of "children may experience when living with PKU" (as crianças com PKU podem viver). They could not catch the abstraction related to "podem viver."

This was not an issue for the adolescents, adults and parents.
The translation was simplified as follows: coisas que podem acontecer com crianças com fenilcetonúria (fenil). The choice of "acontecer" (to happen) was found more colloquial and easier to understand in this context.

"Acontecer" was applied to the three other versions (Adolescent, Adult and Parent) in an effort of harmonization.

Domain "YOUR FEELINGS IN GENERAL ABOUT PKU”

Children - Item 32. Visiting my doctor for PKU bothers me Adolescents - Item 48. Visiting my doctor/dietician for PKU bothers me Adults - Item 53. Visiting my doctor/ C/Sy dietician for PKU bothers me Parents - Item 40. Visiting my child's doctor/dietician for PKU bothers me

Children, Adolescents, Adults Having PKU makes me angry Parents - PKU makes me angry

\section{It is hard for me}

(used in several items in Children,

Adolescents and Adults versions)
Usually in Brazil, children are followed by dieticians.

Dieticians suggested replacing "my doctor" and "my doctor/dietician" by "medical visits."

One child respondent had difficulty in understanding the concept of anger in this context. Adult respondents suggested changing "com raiva" by "revoltado."

The literal translation of "It is hard for me" (É difícil para mim) sounded too awkward for the translators.
Following the dieticians' advice, translators decided to make the translation less exclusive and only refer to visits, hence "Ir às consultas por causa da fenil" (BT**: Going to medical visits because of PKU"). For the parents' version, the syntax was slightly modified by moving the genitive case from doctor to PKU: i.e., Ir às consultas por causa da fenil do meu filho/ da minha filha me aborrece (BT**: "Going to medical visits because of my son's/ daughter's phenylketonuria annoys me").

As "angry" implies feeling of unfairness because of having PKU, i.e., the patients wonder why they have PKU and not others, the suggested change, i.e., "revoltado", was implemented in all versions.

Translator decided to use "I find it difficult" (Eu acho difícil). 
Table 3. Cont.

\begin{tabular}{|c|c|c|c|c|c|}
\hline \multirow{2}{*}{$\begin{array}{l}\text { Title/Instructions/ltems/ } \\
\text { Response Categories } \\
\text { Original UK version }\end{array}$} & \multirow[b]{2}{*}{ Diff.* } & \multicolumn{2}{|c|}{ LV§ Step } & \multirow[b]{2}{*}{ Description } & \multirow[b]{2}{*}{ Solutions } \\
\hline & & CI* & $\mathbf{R} *$ & & \\
\hline \multicolumn{6}{|c|}{ Specific to PKU-QOL Child version } \\
\hline Main Instructions & & & & & \\
\hline
\end{tabular}

Translators suggested replacing "how things have been for you" (como as coisas tem sido com Put an " $X$ " in the circle in order to
tell us how things have been for you. $\quad \mathrm{S} \quad \checkmark \quad$ você) by "how you have been feeling" (como você tem se sentido) to make the sentence easier to understand.

Two respondents had difficulties understanding the concept.

\section{Example:}

During my holidays, I sleep more

S
The suggestion was accepted by the local consultant as being compliant with the list of concepts.

than when I go to school

One respondent was unable to understand the item. The team

Item 28. In the past 7 days, it was hard to do everything I needed to do $\mathrm{S}$ for my PKU thought it was a conceptual issue

as, most of the times, parents are the one measuring, calling the dietician, or preparing the food,

etc.
"When I go to school" (quando vou à escola) was replaced by "during the classes" (durante as aulas).

Domain "YOUR DAILY LIFE WITH PKU”

\section{Domain "YOUR FEELINGS IN GENERAL ABOUT PKU"}

Instructions:

Following are some things that some children may feel about their PKU.

\begin{abstract}
children may feel about their PKU.
\end{abstract}
Item 31. I am worried that my levels are high

Translators thought that the direct translation of "feel about" was not adapted and would be difficult to understand.
No change to the translation. 
Table 3. Cont.

\begin{tabular}{|c|c|c|c|c|c|c|}
\hline \multirow{2}{*}{$\begin{array}{l}\text { Title/Instructions/Items/ } \\
\text { Response Categories }\end{array}$} & \multicolumn{4}{|c|}{ LV§ Step } & \multirow[b]{2}{*}{ Description } & \multirow[b]{2}{*}{ Solutions } \\
\hline & Diff.* & F/B* & $\mathbf{C l} *$ & $\mathbf{R}^{*}$ & & \\
\hline
\end{tabular}

The issues were twofold:

Translation of "I feel bad" and of "I

am not allowed."

At first "bad" was translated by "culpado" (guilty). This was well

Item 39. I feel bad about myself after eating or drinking something I am not allowed

Item 40. I feel bad about myself if I

miss taking a supplement understood by patients. However,

adolescents suggested that the

intitial translation of "bad" by

"culpado(a)" was not relevant and proposed "arrependido(a)" (regretful).

For idiomatic reasons, the dieticians suggested replacing "não é permitida" (is not allowed) by "não posso" (I can't).
"Arrependido(a)" was used to translate "bad" in the Children and Adolescent versions.

"Não posso" (I can't) was kept in the final Children version.
One respondent found the word "confidenciais" difficult.

"Anônimas" was found either not clear or difficult to understand by two other respondents.
No change to the translation. will remain strictly confidential and

anonymous.
Item 4b. If you felt this, do you think it was related to PKU?

Item 9b. If you had this, do you think it was related to PKU?
The literal translation "Se você sentiu isso/ Se você teve isso, você acha que isso estava relacionado..." was found poor because of the repetition of "isso" (this).
Translators decided to repeat the construction of:

- Item 4a, i.e., I was tired during the day. The final version was as follows: Se você ficou cansado(a) durante o dia, você acha que isso estava relacionado com..." (BT**: If you were tired during the day, do you think it was related to...).

- Item 9a, i.e., I had mood swings. The final version was as follows: Se você teve mudanças de humor, você acha que isso estava relacionado com a fenil? (BT**: If you had mood swings, do you think this was related to...? 
Table 3. Cont.

\begin{tabular}{|c|c|c|c|c|c|}
\hline Title/Instructions/Items/ & & $V^{\S} S t$ & & & \\
\hline Response Categories & Diff.* & & & Description & Solutions \\
\hline Original UK version & F/B* & $\mathbf{C l} *$ & $\mathbf{R}^{*}$ & & \\
\hline
\end{tabular}

Domain "YOUR PKU DIET AND SUPPLEMENTS"

Item 22. In the past 7 days, I was embarrassed about eating with other kids, because of my PKU Item 29. In the past 7 days, I was embarrassed about taking my PKU supplements in front of other kids

Item 33. In the past 7 days, I snuck something to eat or drink that I was not supposed to have
Translators challenged the original word "kids" as they argued that adolescents might be more appropriate given the age-range (12-17 years) of the questionnaire.
The word "adolescentes" (BT**: adolescents) was used to replace "crianças" (BT**: kids) in the final version of both items.
The verb "to sneak" is very idiomatic in English. It was not possible to find an equivalent in the translations.
Translators assumed that the concept of taking in a furtive or artful manner so as not to be seen by their parents could be rendered by "escondido(a)" (BT**: hidden). Therefore, the item was translated as follows: "Nos últimos 7 dias, eu comi ou bebi escondido(a) alguma coisa que eu não deveria."

\section{Domain "YOUR DAILY LIFE WITH PKU”}

Item 42. In the past 7 days, it was hard to do everything I needed to do $\mathrm{S}$ for my PKU
One respondent was unable to understand the item, and another one found it irrelevant. The team thought it was a conceptual issue as, most of the times, parents are the one measuring, calling the dietician, or preparing the food, etc. (Same issue as for the children version).
No change to the translation.

Domain "YOUR FEELINGS IN GENERAL ABOUT PKU"

Item 47. I am worried that my Phe/ protein levels are high

Item 57. I feel guilty after eating or drinking something I am not supposed to S Item 58. I feel guilty if I miss taking a supplement
Dieticians suggested changing Phe/ protein by "Phenylalanine levels" (níveis de fenilalanina) as it is the usual way of talking about protein levels.

Adolescents suggested that the initial translation of "bad" by "culpado(a)" was not relevant and proposed "arrependido(a)" (regretful).
The item was translated as follows: Eu fico preocupado(a) que meus níveis de fenilalanina estejam altos (BT**: I get worried that my levels of phenylalanine are high).

The suggestion was accepted and implemented in the Adolescent and Child version. 
Table 3. Cont.

\begin{tabular}{|c|c|c|c|c|c|c|}
\hline \multirow{2}{*}{$\begin{array}{l}\text { Title/Instructions/ltems/ } \\
\text { Response Categories } \\
\text { Original UK version }\end{array}$} & \multirow[b]{2}{*}{ Diff.* } & \multicolumn{3}{|c|}{ LV§ Step } & \multirow[b]{2}{*}{ Description } & \multirow[b]{2}{*}{ Solutions } \\
\hline & & F/B* & Cl* & $\mathbf{R} *$ & & \\
\hline \multicolumn{7}{|c|}{ Domain "YOUR FEELINGS IN GENERAL ABOUT PKU” } \\
\hline $\begin{array}{l}\text { Item } 64 \text {. I feel guilty if I miss taking } \\
\text { a supplement } \\
\text { Item } 65 \text {. I feel guilty after eating } \\
\text { or drinking something I am not } \\
\text { supposed to }\end{array}$ & $S$ & $\checkmark$ & & & $\begin{array}{l}\text { The translation of "guilty" was } \\
\text { not an issue in the first round of } \\
\text { translation. However, following } \\
\text { the adolescents' interviews, } \\
\text { it was decided to switch to } \\
\text { "arrependido(a)" (regretful). }\end{array}$ & $\begin{array}{l}\text { The word "arrependido(a)" was } \\
\text { implemented in the Adult version. }\end{array}$ \\
\hline \multicolumn{7}{|c|}{ Domain “YOUR CHILD'S PKU DIET AND SUPPLEMENTS” } \\
\hline $\begin{array}{l}\text { Item } 14 \text {. In the past } 7 \text { days, it was } \\
\text { hard to make sure that my child got } \\
\text { enough calories }\end{array}$ & S & & & $\checkmark$ & $\begin{array}{l}\text { The dieticians asked to add } \\
\text { "energia" (energy) after calories, } \\
\text { as Brazilian parents commonly use } \\
\text { this word. }\end{array}$ & $\begin{array}{l}\text { The following change was implemented: } \\
\text { calorias/energia. }\end{array}$ \\
\hline
\end{tabular}

$\S L V$ : Linguistic Validation

*Diff: Difficulties; F/B: issues discussed at forward/backward steps; Cl: issues discussed during cognitive interviews; R: issues discussed during the dieticians' and sponsor's review; **BT: backward translation

A major effort of harmonization was conducted throughout the process, making sure to apply the most appropriate wording to all versions when an interesting solution was found in particular during the cognitive interviews. For instance, the verbal form "may experience" in the instructions of the domain "Your daily life with PKU", originally translated to "podem viver" was changed to "podem acontecer" (may happen) in all versions following the interviews with the children.

\section{Discussion}

The adaptation of the PKU-QOL questionnaire from British English to Brazilian Portuguese did not reveal major semantic or cultural issues. Participating patients with PKU and their caregivers provided input essential to the adaptation of the PKU-QOL questionnaire so that each component could be easily understood by the Brazilian target population. The PKU-QOL questionnaire was well accepted by the participants of the study, which supports the assumption that concepts assessed and identified during the development of the original PKU-QOL questionnaire [19] were equally relevant to the Brazilian patients and their caregivers. The main limitations of our research were the following: 1) the use of a convenience sample that represents only a part of the entire population of patients with PKU and their caregivers in Brazil; 2) the research was performed with a PKU population from the most developed Brazilian state in educational and economic aspects [24]; and 3) we did not recruit patients based on their phenotype. Our intent was to test how well the patients understood the questionnaire, and whether or not the wording was clear and explicit, and not to test the content validity of the Brazilian PKU-QOL. Nevertheless, we acknowledge that, for the future use of the PKU-QOL, disease phenotype is relevant as it impacts the degree of dietary PHE restriction. When the PKU-QOL questionnaires are updated in the future, they are intended to include a sentence acknowledging that some patients may not require some treatment components (medical food, special low protein food, etc.), and that the questions should be answered accordingly.

Besides the initial papers published on the development and use of the PKU-QOL questionnaire in eight countries [18-20], published research on cross-cultural perspectives of quality of life of patients with PKU is limited [25]. Most of the cross- 
cultural evaluations currently published review diagnostic and management perspectives in various countries or contexts such as immigration [26-31]. The availability of the PKU-QOL questionnaire in nine countries (Brazil, France, Germany, Italy, The Netherlands, Spain, Turkey, UK and the USA) will enable cross-cultural research in PKU, and might be the first step to use in various cultural settings. International studies assessing differences of impact across cultures would allow cross-cultural comparisons and improve awareness, tracking, and management of impact on HRQL in patients with PKU in different cultures, thus providing opportunity for increased support. In addition, the cross-cultural equivalence of the nine language versions of the PKU-QOL questionnaire (due to the use of rigorous crosscultural methodologies [19-20] during the development phase) will enable the pooling of data gathered in different countries, and optimize the chance of demonstrating treatment benefit. This will be useful in assessing the impact of standard dietary treatment, pharmacological treatments such as sapropterin, and potential new therapies on clinical outcomes.

Thanks to the availability of the PKU-QOL questionnaire into Brazilian Portuguese, the patients' perceptions in Brazil will be assessed and documented as patients age. This will enable increased understanding of the impact of PKU on the HRQL of patients and their parents throughout their life cycle. The PKUQOL questionnaire is a validated tool and its use in assessing the impact of standard dietary therapy, pharmacological treatments such as sapropterin, and potential new therapies on the patients' and their caregivers' lives will be valuable in the management of patients with PKU in the future. In addition, the use of this instrument will encourage consistent collection of data across treatment centers in Brazil.

\section{Conclusions}

The adaptation of the British English PKU-QOL questionnaire into Brazilian Portuguese did not raise major semantic and cultural issues. The four versions of the PKU-QOL questionnaire are now fully linguistically validated in Brazilian Portuguese. The PKU-QOL questionnaire will be valuable for Brazilian healthcare providers in individualizing treatment and managing patients with PKU.

\section{Acknowledgements}

We are extremely grateful to the patients, caregivers and the clinician who have contributed to this study.

\section{Funding}

The study was funded by BioMarin Pharmaceutical Inc.

\section{Abbreviations}

BH4: tetrahydrobiopterin; C: Cultural; HRQL: Health-related quality of life; I: Idiomatic; KINDL: Kinder Lebensqualität; PAH: Phenylalanine hydroxylase; PHE: Phenylalanine; PKU: Phenylketonuria; PKU-QOL: Phenylketonuria - quality of life; QOL: Quality of life; S: Semantic; Sy: Syntactic; TYR: Tyrosine. UK: United Kingdom; USA: United States of America.

\section{Declarations}

\section{Ethics approval and consent to participate}

All study subjects gave informed, written consent prior to their participation; consent on behalf of all children taking part was given in writing by their parents or guardians. No submission to Ethical Committee was required.

\section{Competing interests}

EJ is an employee and stock owner of BioMarin Pharmaceutical Inc., USA. FV and DG are employees of BioMarin Brasil Farmacêutica Ltda, Brazil. CA is an employee of Mapi, France, an ICON plc Company, a consulting company commissioned by BioMarin Pharmaceutical Inc., USA. ARF and EL are dieticians and employees of APAE (São Paulo and Salvador, Brazil). LG is a dietician, and an employee of the Hospital das Clínicas de Porto Alegre, Brazil.

\section{Authors' contributions}

EJ, FV and DG managed and participated in the design of the project, provided clinical and scientific expertise about PKU and critically reviewed the manuscript. ARF, EL and LG provided their expertise as dieticians and critically reviewed the manuscript. CA analyzed the data generated at each step, designed the categorization of translation difficulties, participated in the interpretation of results, and drafted the manuscript. All authors read and approved the final manuscript.

\section{Declaration of Conflicting Interests}

The author(s) declared no potential conflicts of interest with respect to the research, authorship, and/or publication of this article.

\section{Intellectual property and condition of use}

The PKU-QOL questionnaire is available in four versions: Child PKU-QOL, Adolescent PKU-QOL, Adult PKU-QOL and Parent PKU-QOL. The PKU-QOL is protected by international copyright - PKU-QOL @ BioMarin Pharmaceutical Inc. - 2015 - All Rights Reserved. The PKU-QOL is available freely for use in individual medical practice and in non-privately funded academic research. Access to the questionnaire, as well as further 
information on, or permission to use the PKU-QOL and/or translations, can be found on <https:/eprovide.mapi-trust.org/ instruments/phenylketonuria-impact-and-treatment-qualityof-life-questionnaire $>$. Potential users will have to create an account on eProvide (link to <https://eprovide.mapi-trust.org/ register $>$ ) and specify in the Organization field that they are a clinician. This categorization will enable free access to the PKU-QOL and its translations.

A software called "PKU-QoLC Electronic scorer" is available to ease the calculation of PKU-QOL scores for all four versions. This software and QuickStart guide can be downloaded from the following link: <https://iconplc.box.com/v/PKU-QOLelectronic-scorer $>$.

\section{References}

1. Blau N, van Spronsen FJ, Levy HL. Phenylketonuria. Lancet. 2010;376(9750):1417-1427. doi: 10.1016/S01406736(10)60961-0

2. Waisbren SE, Noel K, Fahrbach K, et al. Phenylalanine blood levels and clinical outcomes in phenylketonuria: a systematic literature review and meta-analysis. $\mathrm{Mol}$ Genet Metab. 2007;92(1-2):63-70. doi: 10.1016/j. ymgme.2007.05.006

3. Vockley J, Andersson HC, Antshel KM, et al; American College of Medical Genetics and Genomics Therapeutics Committee. Phenylalanine hydroxylase deficiency: diagnosis and management guideline. Genet Med. 2014;16(2):188-200. doi: 10.1038/gim.2013.157

4. Camp KM, Lloyd-Puryear MA, Huntington KL. Nutritional treatment for inborn errors of metabolism: indications, regulations, and availability of medical foods and dietary supplements using phenylketonuria as an example. Mol Genet Metab. 2012;107(1-2):3-9. doi: 10.1016/j. ymgme.2012.07.005

5. Singh RH, Rohr F, Frazier D, et al. Recommendations for the nutrition management of phenylalanine hydroxylase deficiency. Genet Med. 2014;16(2):121-131. doi: 10.1038/ gim.2013.179

6. Giovannini M, Verduci E, Salvatici E, Paci S, Riva E. Phenylketonuria: nutritional advances and challenges. Nutr Metab (Lond). 2012;9(1):7. Lond. doi: 10.1186/17437075-9-7

7. Enns GM, Koch R, Brumm V, Blakely E, Suter R, Jurecki E. Suboptimal outcomes in patients with PKU treated early with diet alone: revisiting the evidence. Mol Genet Metab. 2010;101(2-3):99-109. doi: 10.1016/j.ymgme.2010.05.017

8. Bosch AM, Tybout W, van Spronsen FJ, de Valk HW, Wijburg FA, Grootenhuis MA. The course of life and quality of life of early and continuously treated Dutch patients with phenylketonuria. J Inherit Metab Dis. 2007;30(1):29-34. doi: 10.1007/s10545-006-0433-6
9. Bosch AM, Maurice-Stam H, Wijburg FA, Grootenhuis MA. Remarkable differences: the course of life of young adults with galactosaemia and PKU. J Inherit Metab Dis. 2009;32(6):706-712. doi: 10.1007/s10545-009-1253-2

10. Landolt MA, Nuoffer JM, Steinmann B, Superti-Furga A. Quality of life and psychologic adjustment in children and adolescents with early treated phenylketonuria can be normal. J Pediatr. 2002;140(5):516-521. doi: 10.1067/ mpd.2002.123663

11. Gassió R, Campistol J, Vilaseca MA, Lambruschini N, Cambra FJ, Fusté E. Do adult patients with phenylketonuria improve their quality of life after introduction/resumption of a phenylalanine-restricted diet? Acta Paediatr. 2003;92(12):1474-1478. doi: 10.1111/j.1651-2227.2003. tb00834.x

12. Simon E, Schwarz M, Roos J, et al. Evaluation of quality of life and description of the sociodemographic state in adolescent and young adult patients with phenylketonuria (PKU). Health Qual Life Outcomes. 2008;6(1):25. doi: 10.1186/1477-7525-6-25

13. Bik-Multanowski M, Didycz B, Mozrzymas R, et al. Quality of life in noncompliant adults with phenylketonuria after resumption of the diet. J Inherit Metab Dis. 2008;31(Suppl 2): 415-418. doi: 10.1007/s10545-008-0978-7

14. Ziesch B, Weigel J, Thiele A, et al. Tetrahydrobiopterin $\left(\mathrm{BH}^{4}\right)$ in PKU: effect on dietary treatment, metabolic control, and quality of life. J Inherit Metab Dis. 2012;35(6):983-992. doi: 10.1007/s10545-012-9458-1

15. Thimm E, Schmidt LE, Heldt K, Spiekerkoetter U. Healthrelated quality of life in children and adolescents with phenylketonuria: unimpaired HRQoL in patients but feared school failure in parents. J Inherit Metab Dis. 2013;36(5):767-772. doi: 10.1007/s10545-012-9566-y

16. Demirdas S, Maurice-Stam H, Boelen CC, et al. Evaluation of quality of life in PKU before and after introducing tetrahydrobiopterin ( $\mathrm{BH} 4)$; a prospective multi-center cohort study. Mol Genet Metab. 2013;110(suppl):S49-S56. doi: 10.1016/j.ymgme.2013.09.015

17. Cazzorla C, Cegolon L, Burlina AP, et al. Quality of Life (QoL) assessment in a cohort of patients with phenylketonuria. BMC Public Health. 2014;14(1):1243. doi: 10.1186/1471-2458-14-1243

18. Bosch AM, Burlina A, Cunningham A, et al. Assessment of the impact of phenylketonuria and its treatment on quality of life of patients and parents from seven European countries. Orphanet J Rare Dis. 2015;10(1):80. doi: 10.1186/ s13023-015-0294-x

19. Regnault A, Burlina A, Cunningham A, et al. Development and psychometric validation of measures to assess the impact of phenylketonuria and its dietary treatment on patients' and parents' quality of life: the phenylketonuria - quality of life (PKU-QOL) questionnaires. Orphanet $J$ Rare Dis. 2015;10(1):59. doi: 10.1186/s13023-015-0261-6 
20. Jurecki E, Cunningham A, Birardi V, Gagol G, Acquadro C. Development of the US English version of the phenylketonuria - quality of life (PKU-QOL) questionnaire. Health Qual Life Outcomes. 2017;15(1):46. doi: 10.1186/ s12955-017-0620-1

21. Mear I, Giroudet C. Linguistic Validation Procedures. In: Acquadro C, Conway K, Giroudet C, Mear I, eds. Linguistic Validation Manual for Health Outcome Assessments. Lyon, France: Mapi Institute; 2012:15-117:chap 1.

22. Wild D, Grove A, Martin M, et al; ISPOR Task Force for Translation and Cultural Adaptation. Principles of Good Practice for the Translation and Cultural Adaptation Process for Patient-Reported Outcomes (PRO) Measures: report of the ISPOR Task Force for Translation and Cultural Adaptation. Value Health. 2005;8(2):94-104. doi: 10.1111/j.1524-4733.2005.04054.x

23. Wild D, Eremenco S, Mear I, et al. Multinational trialsrecommendations on the translations required, approaches to using the same language in different countries, and the approaches to support pooling the data: the ISPOR PatientReported Outcomes Translation and Linguistic Validation Good Research Practices Task Force report. Value Health. 2009;12(4):430-440. doi: 10.1111/j.1524-4733.2008.00471.x

24. United Nations Development Programme, Institute of Applied Economic Research, João Pinheiro Foundation. Atlas of Human development in Brazil. http://atlasbrasil. org.br/2013/en/ranking. Last accessed 09/11/2018.

25. Keil S, Anjema K, van Spronsen FJ, et al. Long-term followup and outcome of phenylketonuria patients on sapropterin: a retrospective study. Pediatrics. 2013;131(6):e1881-e1888. doi: $10.1542 /$ peds.2012-3291
26. Giżewska M, MacDonald A, Bélanger-Quintana A, et al. Diagnostic and management practices for phenylketonuria in 19 countries of the South and Eastern European Region: survey results. Eur J Pediatr. 2016;175(2):261-272. doi: 10.1007/s00431-015-2622-5

27. Zerjav Tansek M, Groselj U, Angelkova N, et al. Phenylketonuria screening and management in southeastern Europe - survey results from 11 countries. Orphanet J Rare Dis. 2015;10(1):68. doi: 10.1186/s13023015-0283-0

28. Trefz FK, van Spronsen FJ, MacDonald A, et al. Management of adult patients with phenylketonuria: survey results from 24 countries. Eur J Pediatr. 2015;174(1):119-127. doi: 10.1007/s00431-014-2458-4

29. Mei L, Song P, Kokudo N, Xu L, Tang W. Current situation and prospects of newborn screening and treatment for Phenylketonuria in China - compared with the current situation in the United States, UK and Japan. Intractable Rare Dis Res. 2013;2(4):106-114. doi: 10.5582/irdr.2013. v2.4.106

30. Stockler S, Moeslinger D, Herle M, Wimmer B, Ipsiroglu OS. Cultural aspects in the management of inborn errors of metabolism. J Inherit Metab Dis. 2012;35(6):1147-1152. doi: 10.1007/s10545-012-9455-4

31. Ipsiroglu OS, Herle M, Spoula E, et al. Transcultural pediatrics: compliance and outcome of phenylketonuria patients from families with an immigration background. Wien Klin Wochenschr. 2005;117(15-16):541-547. doi: 10.1007/s00508-005-0327-x 